\title{
COMPARISON OF SELECTED SHADING CORRECTION METHODS
}

doi: $\quad 10.2478 /$ czoto-2019-0105

Date of submission of the article to the Editor: 18/11/2018

Date of acceptance of the article by the Editor: 07/01/2019

\author{
Aneta Gądek-Moszczak ${ }^{1}$ - orcid id: 0000-0002-4266-6711 \\ Leszek Wojnar ${ }^{1}$ - orcid id: 0000-0001-8786-3535 \\ Adam Piwowarczyk ${ }^{1}$ \\ ${ }^{1}$ Cracow University of Technology, Institute of Applied Informatics, Poland, \\ aneta.moszczak@gmail.com
}

\begin{abstract}
Shade effect is a defect of the images very often invisible for human vision perception but may cause difficulties in proper image processing and object detection especially if the aim of the task is to proceed detection and quantitative analysis of the objects. There are several methods in image processing systems or presented in the literature, however some of them introduce unexpected changes in the images, what may interfere the final quantitative analysis. In order to solve this problem, authors proposed a new method for shade correction, which is based on simulation of the image background based on analytical methods which return pixel values representing smooth grey level changes. Comparison of the effects of correction by applying standard methods and the method proposed are presented.
\end{abstract}

Keywords: image analysis, shade correction, image distortion

\section{INTRODUCTION}

One of the most common problems in image analysis is uneven background, which may disable proper detection of the objects and their further reliable quantitative analysis (Russ, 1995; Wojnar et al., 2002). The shadow is a one of the fails of acquisition stage and it is caused by unequal lighting of the objects, especially in the case of light microscopy (Gądek-Moszczak, 2017; Gądek-Moszczak and Matusiewicz, 2017). The images may be brighter in the center and the intensity of the image decreases at the border of the field of view. Shading effect leads to difficulties in proper objects detection, especially in algorithms with automatic threshold. This illumination heterogeneity, even as inconsiderable so invisible for human eye, in some cases, like for instance on the images with low contrast between the objects and background, may have an impact on an improper objects detection and their further quantitative assessment. This problem is present in images from various sources, like for example light microscopes, digital cameras or telescopes. It is appear in a wide range of studies from different fields of science: biology, medicine, material science, geodesy, cartography (analysis of the satellite images or images gathered by drones), 
astronomy, etc. Because this image distortion might be a serious obstacle in successful image analysis process and causes the setback of the proper objects detection, several methods to minimize or reduce the shade effect in the images were developed (Likar et al., 2000).

Generally, the assumption which lays on the basis of most of the shade correction methods is to extract from a distorted image the factor which is the source of the problem, namely the image of the shade. Then the image of the shade is obtained, it's negative is used to correct the initial image by applying it to the initial image. It should be stressed out that all operation on images, like filtering, morphological or arithmetic operations introduce to the initial image unwanted additional information and may change the results of the analysis. Thus selection of the proper correction methods adequately to the analyzed image and present shade is very important. This has a positive effect on analyzes in the area of materials science (Dudek, 2009; Ulewicz et al., 2010; Radzyminska-Lenarcik and Ulewicz, 2014; Krawczyk et al., 2018), especially based on automatic or semi-automatic image analysis of microscopic images (Weglowski and Osocha, 2009; Wlodarczyk, 2011; Szabracki and Lipinski, 2014). It is also a useful auxiliary tool in the analysis of a metal microstructure, modified by additives (Lipinski, 2010; Szczotok and Rodak, 2012) or treatments (Lipinski and Wach, 2014; Szczotok and Chmiela, 2014), or properties of a modified surface layer (Tofil et al., 2018; Witkowski et al., 2018). The method finds the same and even greater usability in the analysis of polymer structures (Ulewicz et al., 2003; Ulewicz et al., 2007; Ulewicz et al., 2011; Gądek et al., 2006; Gawdzinska et al., 2018).

\section{METHODOLOGY OF RESEARCH}

Four methods commonly used for shade correction in image processing algorithms were chosen. In general the methods of shade correction may be distinguished in two groups, according to the methods of shading estimation. The first one estimated the shadow in posteriori, based on the image with uneven illumination, for the purpose of the test three example methods Morphological, Mean, and Proportional were chosen, The second group of shade correction methods estimates the shade a priori, if it is possible to grab the test image containing shade. In order to follow up the test of efficiency of different methods of shade correction, a method called in this project as Black-White was chosen.

In the Morphological method the image of shadow is obtained by large closing transformation. Closing transformation consists of two basic morphological operations, applied consecutively: dilation and erosion. Dilation in grey scale images corresponds to maximum filtering and erosion is equal to minimum filtering. Size of the structuring element in closing should be larger than the biggest size of the object in the image in order to induce high blurring of the image, where the objects are not visible. Next, negative of the shade image is added to the initial image, reducing the shading effect.

The Mean method is based on the arithmetic mean value of the analyzed pixels. The mask of the mean filter should be large enough to obtain the image of the shadow as a result. Similarly to the previous method the negative added to the initial image causes reduction of uneven illumination. 
The third method is called Proportional (Gądek and Wojnar, 2003). In this method the image of the shadow is obtained by closing transformation and then used to generate the image in which the pixel values are equal to coefficients allowing correction of the illumination of the image proportionally. This is the essential difference compared with morphological or mean methods. It is obtained by subtracting the image of the shadow from the initial image (filled with 255 value) and result is multiplied by the image of the shade negative. Finally the result image is added to the initial image, what results in corrected image.

Black-White method of shade correction is effective in the situation when it is possible to obtain the test image with uneven illumination. The use of this method requires two images: black image with no light and the white image with full illumination. The final image is obtained by the following procedure:

$$
\text { final image }=\text { constant } \cdot \frac{\text { initial image-black }}{\text { white-black }}
$$

The constants in equation (1) is introduced in order to to obtain the desired range of values in the final image. If the acquisition of white and black images is impossible, then they may be replaced by the images generated from the initial image. The white image may be replaced by result of the Gaussian filtering and black by its negative.

In order to assess the effectiveness of all the tested methods the sample image was prepared. Shade mimicking the lighting failure of the microscope was generated. Next it was superimposed onto the image of the iron cast microstructure image (Fig. 1). To assess the results the profile was used. Profile is the interactive measurement tool which records the values of grey level values of the pixels on the image along the test line, and plots it as a curve (Fig. 1b). Profile in referred analyses was placed on all the test images in the diagonal of image window (Fig. 1a).

a)

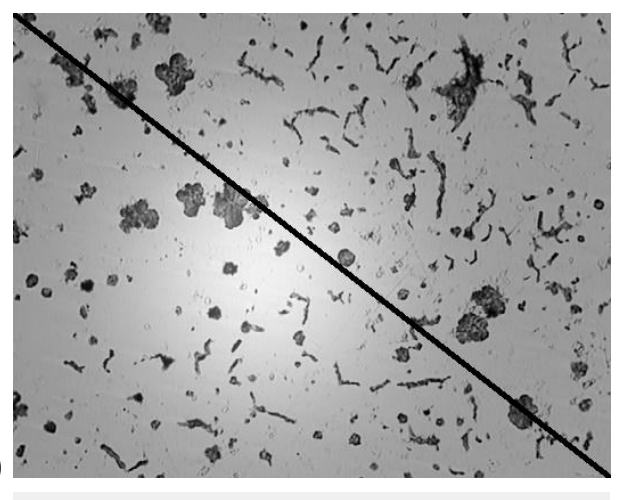

b)

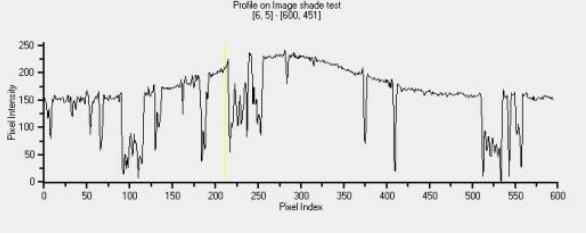

Fig. 1. Test image (example of the microstructure of the cast iron) observed in light microscope (a) and its profile (b)

All methods were programmed in the Aphelion software for image processing and analysis. Black-White method is the one of proposed filters for shading correction attached in Aphelion's filters library. 


\section{RESULTS}

Correction of the shade was performed by all the above described methods and the final images were compared. Comparison of the corrected images was performed by visual analysis of final images, its profiles, and finally, effects of detection by thresholding (Fig. 2 up to Fig. 6).

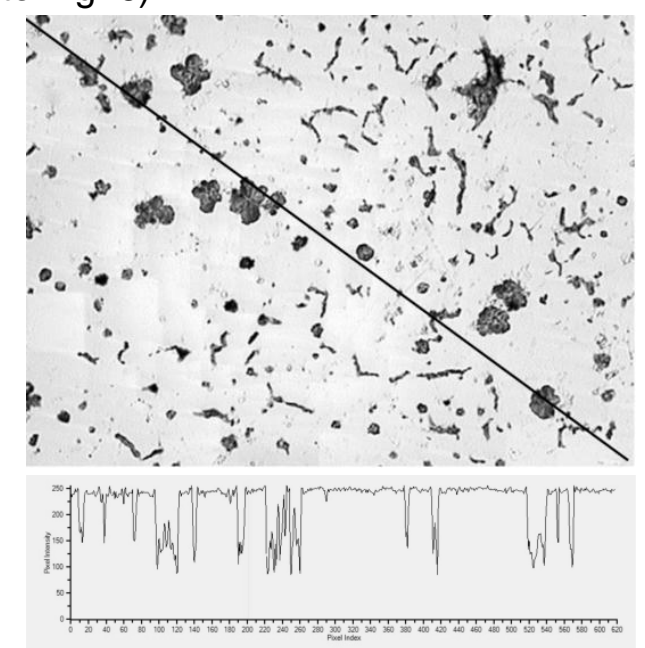

Fig. 2. Image after shading correction performed by Morphological method with the profile

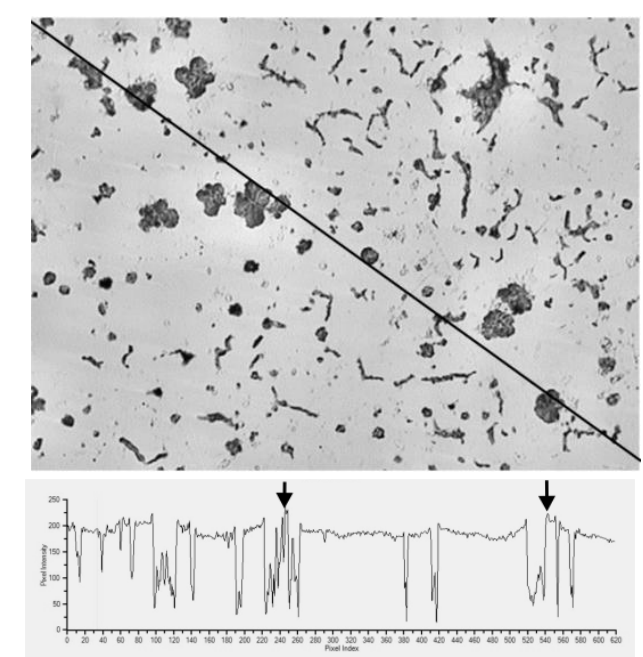

Fig. 3. Image after shading correction performed by Mean method with the profile

Binary images of all images with reduced shade were performed applying automatic threshold algorithm according to Otsu method (Fig. 6).

Comparison of the final images corrected by all tested methods (Fig. 2, Fig. 3, Fig. 4, Fig. 5) showed that the goal of transformation was obtained and the images present have no shade. Visual assessment of the images found the confirmation in the shapes of the curves on the charts presented the profiles. On the all charts the curve presenting the background is on the same level across the image. 


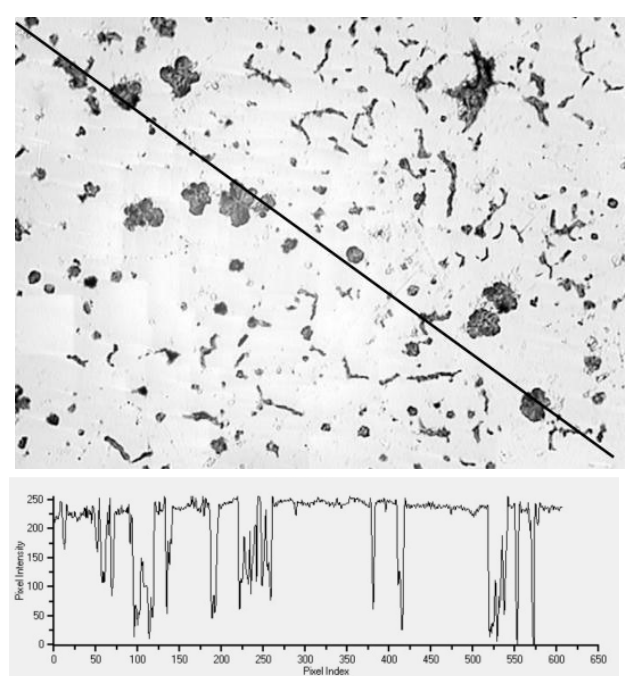

Fig. 4. Image after shading correction performed by Proportional method with the profile

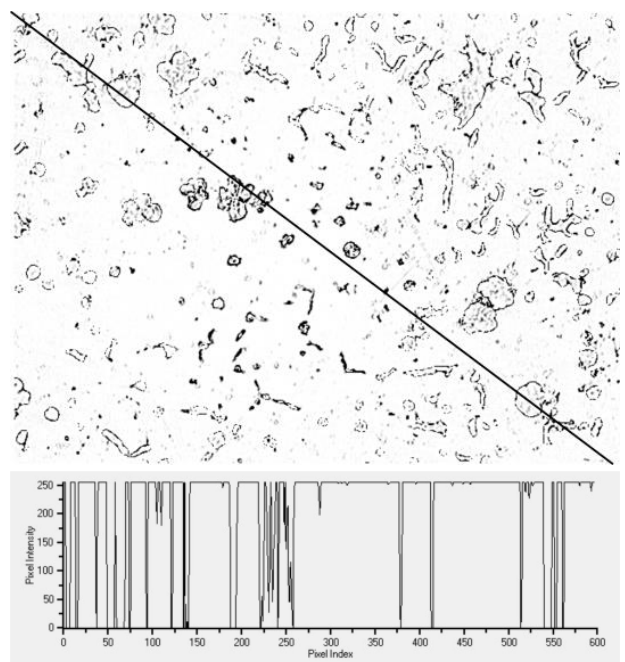

Fig. 5. Image after shading correction performed by $B \& W$ method with the profile

When analyzing the image after correction by the Morphological method it can be observed that whole image is much brighter than the test one. The range of the values of all pixels increased. The result of the binarization was correct, all graphite's inclusions were detected (Fig. 6a).

Shade correction by Mean method caused the increase in brightness of the background around the particles of the graphite, what can be observed on the corrected image and the profile. The fragments of the profile curve illustrating this side effect of correction are pointed by the arrows (Fig. 3).

Proportional method also delivered rewarding result. The obtained image presents even illumination and higher contrast between the objects and background (Fig. 4). The results of binarization of images corrected by Morphological and Proportional methods are similar.

The last method, Black \& White, delivered the image which deeply changed the initial image, and the particles of the graphite. The image had very high contrast, and the interior of the particles had pixel values similar to the background (Fig. 5). The binary image (Fig. 6d) of corrected images confirmed that this shading correction method degraded the image quality and made impossible its further analysis. 


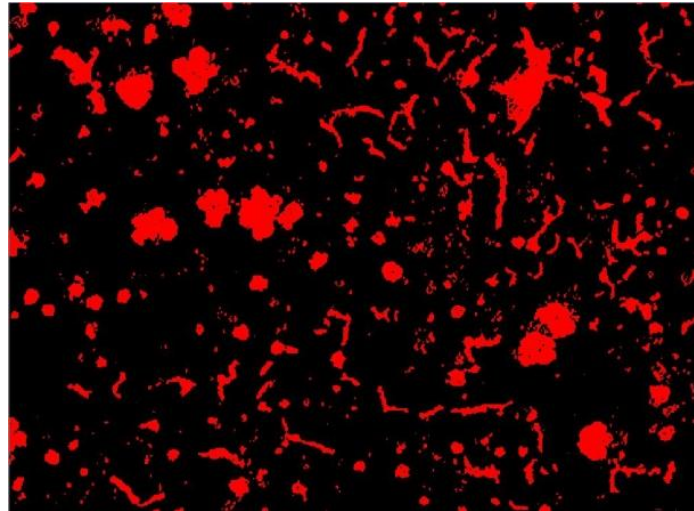

a) Morphological method

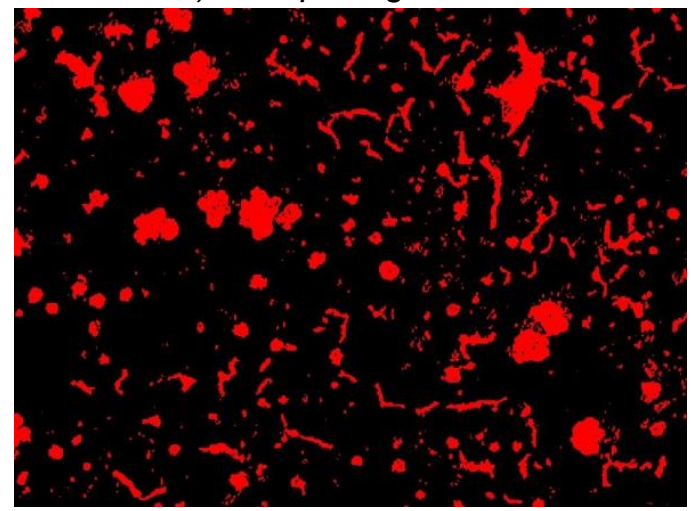

c) Proportional method

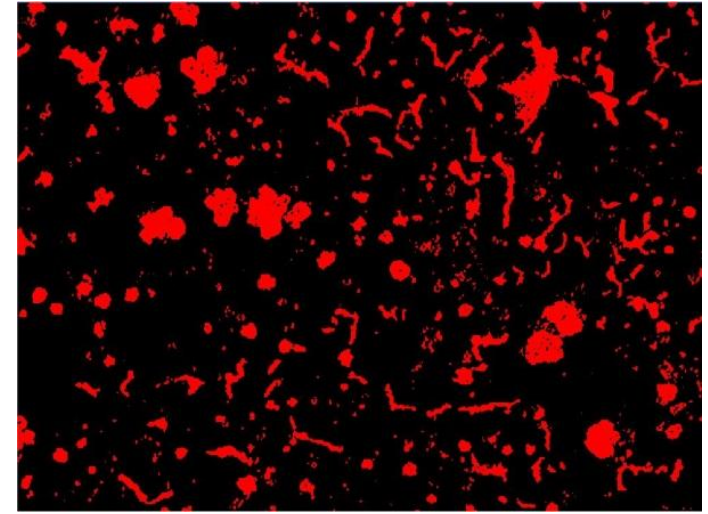

b) Mean method

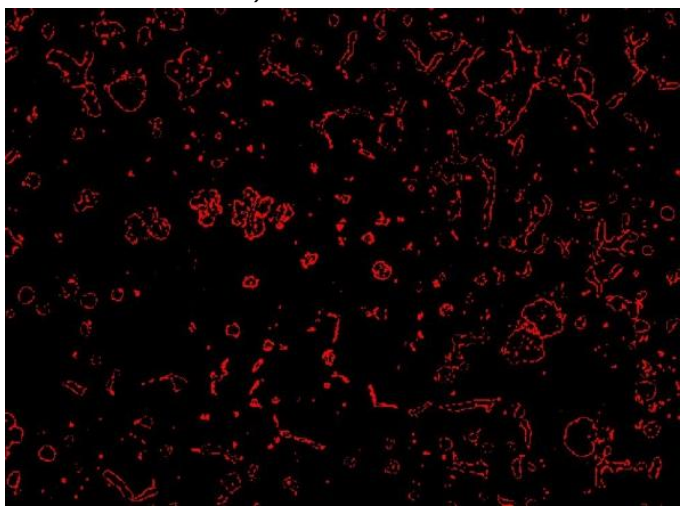

d) B\&W method

Fig. 6. Result of the detection performed on the corrected images by 4 selected methods

\section{CONCLUSIONS}

The presented methods of shading correction are not the only ones, and of course it is possible to developed the method which will be more efficient in reducing uneven illumination. Analysis of the most often applied methods confirmed that on the test image almost all of them led to the image with significantly reduced or removed shade. Each of them may be applied as a part of an automatic algorithm for image processing and analysis, but selection of the proper method should be tested on the exemplary images.

Black \&White method ought to be employed in cases when it is possible to obtain the image with full and zero illumination in the optical system used. Adaptation of this method to more wide application failed, what was confirmed by the binarization result.

\section{REFERENCES}

Dudek, A., 2009, Surface properties in titanium with hydroxyapatite coating. Opt. Appl., 39, 825-831.

Gądek A., Wojnar L., 2003. Wpływ sposobu korekcji cienia i doboru metody detekcji na wyniki ilościowej oceny porowatości / Effect of shade correction and detection method on the results of quantitative porosity assessment. Inżynieria Materiałowa, 3, 111-116 [in Polish].

Gądek, A., Kuciel, S., Wojnar, L., Dziadur, W., 2006. Application of computer-aided analysis of an image for assessment of reinforced polymers structures. Polimery-W 51, 206-211. 
Gądek-Moszczak, A., 2017. History of stereology. Image Anal. Stereol., 36, 151-152. DOI: 10.5566/ias.1867

Gądek-Moszczak, A., Matusiewicz, P., 2017. Polish Stereology - a Historical Review. Image Anal. Stereol., 36, 207-221. DOI: 10.5566/ias.1808

Gawdzinska, K., Gądek-Moszczak, A., Bryll, K., Irska, I., Paszkiewicz, S., 2018. Influence of water absorption on chosen strength properties of single-polymer polyester composites. Polimery, 63, 264-269. DOI: 10.14314/polimery.2018.4.2

Krawczyk, J., Sobczyk, A., Stryczek, J., Walczak, P., 2018. Tests of New Methods of Manufacturing Elements for Water Hydraulics. Mater. Res. Proc., 5, 200-205. DOI: 10.21741/9781945291814-35

Likar, B., Maintz, J.B.A., Viergever, M.A., Pernusi F., 2000. Retrospective shading correction based on entropy minimization. Journal of Microscopy, 197, 285-295.

Lipinski, T., 2010. The structure and mechanical properties of Al-7\%SiMg alloy treated with a homogeneous modifier. Solid State Phenom., 163, pp. 183-186. DOI: 10.4028/www.scientific.net/SSP.163.183

Lipinski, T., Wach, A., 2014. Influence of outside furnace treatment on purity medium carbon steel. Metal 2014: $23^{\text {rd }}$ Int. Conf. Metallurgy and Materials. Tanger, Ostrava, 738-743.

Radzyminska-Lenarcik, E., Ulewicz, M., 2014. The use of 1-alkylimidzoles for selective separation of zinc ions in the transport process across a polymeric inclusion membrane. Physicochem. Probl. Mi. 50, 131-142. DOI: 10.5277/ppmp140112

Russ, J.C., 1995. The image processing handbook. CRC Press, Boca Raton.

Szabracki, P., Lipinski, T., 2014. Influence of sigma phase precipitation on the intergranular corrosion resistance of X2CrNiMoN25-7-4 super duplex stainless steel. Metal 2014: 23rd Int. Conf. Metallurgy and Materials. Tanger, Ostrava, 476-481.

Szczotok, A., Chmiela, B., 2014. Effect of Heat Treatment on Chemical Segregation in CMSX-4 Nickel-Base Superalloy. J. Mater. Eng. Perform., 23, 2739-2747. DOI: 10.1007/s11665-013-0843-1

Szczotok, A., Rodak, K., 2012. Microstructural studies of carbides in MAR-M247 nickel-based superalloy. Conf. Technologies and Properties of Modern Utilised Materials, IOP, vol. 35, art. 012006. DOI: 10.1088/1757-899X/35/1/012006

Tofil, Sz., Mulczyk, K., Witkowski, G., 2018. Surface micromachining of titanium alloys with picosecond laser to increase the adhesion force in glued joints. Proc. SPIE, 10974, art. 109740Q, DOI: 10.1117/12.2516646

Ulewicz, M., Walkowiak, W., Brandt, K., Porwolik-Czomperlik, W., 2003. Ion flotation of zinc(II) and cadmium(II) in the presence of side-armed diphosphaza-16-crown-6 ethers. Sep. Sci. Technol. 38, 633-645. DOI: 10.1081/SS-120016655

Ulewicz, M., Sadowska, K., Biernat, J.F., 2007. Selective transport of $\mathrm{Pb}(\mathrm{II})$ across polymer inclusion membrane using imidazole azocrown ethers as carriers. Physicochem. Probl. Miner. Process., 41, 133-143.

Ulewicz, M., Lesinska, U., Bochenska, M., 2010. Transport of lead across polymer inclusion membrane with p-tert-butylcalix[4]arene derivative. Physicochem. Probl. Miner. Process., 44(1), 245-256.

Ulewicz, M., Radzyminska-Lenarcik, E., 2011. Transport of metal ions across polymer inclusion membrane with 1-alkylimidazole. Physicochem. Probl. Miner. Process. 46, 119-130. 
Weglowski, B., Osocha, P., 2009. Modelling of creep for $Y$ pipe from ferriticmartensitic P91 steel. Rynek Energii, 6, 140-145.

Witkowski, G., Tofil, Sz., Mulczyk, K., 2018. Surface micro treatment of INCONEL 718 alloys with a picoseconds laser to increase adhesive strength in glued joints. Proc. SPIE, 10974, art. 109740R, DOI: 10.1117/12.2516663

Wlodarczyk, R., Dudek, A., Nitkiewicz, Z., 2011. Corrosion analysis of sintered material used for low-temperature fuel cell plates. Arch. Metall. Mater. 56, 181-186. DOI: 10.2478/v10172-011-0021-0

Wojnar, L., Kurzydłowski, K.J., Szala, J., 2002. Praktyka analizy obrazu / Image analysis practice. Polskie Towarzystwo Stereologiczne, Kraków [in Polish]. 